\title{
Surface Plasmon Resonance Characterization of Virgin Coconut Oil Biodiesel: Detection of Iron Corrosion Using Polypyrrole Chitosan Sensing Layer
}

\author{
Amir Sadrolhosseini, Mohd Maarof Moksin*, \\ Wan Mahmood Mat Yunus and Zainal Abdin Talib \\ Department of Physics, Faculty of Science, Universiti Putra Malaysia, \\ 43400 UPM Serdang, Malaysia
}

(Received January 21, 2011; accepted June 10, 2011)

Key words: $\quad$ biodiesel, virgin coconut oil, SPR sensor, PPy-CHI, dispersion, $\mathrm{Fe}(\mathrm{III})$, corrosion

Surface plasmon resonance was applied to the study of the optical properties of virgin coconut oil biodiesel produced by the mixture of virgin coconut oil and methanol. Experimentally, the refractive indices of the mixture and dispersion curve were determined, and we found that the resonance angle and refractive index depend on the volume percentage of oil. In addition, a polypyrrole-chitosan layer was used to detect iron ions generated because of the corrosiveness of virgin coconut oil biodiesel. The accuracy of the sensor was $0.1 \mathrm{ppm}$ for the detection of iron ions.

\section{Introduction}

The main components of biodiesels are methyl esters derived from the transesterification of fatty acid. In this process, triglyceride (TG) esters are converted into alkyl ester (biodiesel) in the presence of $\mathrm{NaOH}$ or $\mathrm{KOH}$ catalysts. ${ }^{(1)}$ Hence, three moles of methanol must be added to completely convert three chains of triglyceride into methyl ester. ${ }^{(2)}$

Sunflower, soybean, jatropha, palm, and coconut oils are candidates for producing biodiesel. Virgin coconut oil with its high fatty acid content and low price has a high potential for producing biodiesel and reducing the production cost. ${ }^{(1)}$

The quality of biodiesel can be optically examined from its relevant physical

*Corresponding author: e-mail: maarof@science.upm.edu.my 
properties ${ }^{(3)}$ since excess methanol, water, and metal ion concentration may affect the optical properties of biodiesel. These optical properties have been utilized in sensor design for the detection of ions ${ }^{(4)}$ and determination of water content. ${ }^{(5)}$

The corrosiveness of biodiesel, which is indicated by the presence of metal ions in them, is conventionally evaluated using a copper strip. (3) This method is based on copper corrosion, and all laboratories use the standard method based on the American Society for Testing and Materials Standard (ASTM) D 6751. Since biodiesel containers are made from a ferrous alloy, the detection of ferrous ions is significant as well when evaluating biodiesel.

Polypyrrole (PPy) can be oxidized to form a polymer with intrinsic conducting properties. ${ }^{(6)}$ PPy is relatively easy to make by electro-oxidation, and the thin film of PPy attained is chemically stable. The application of polypyrrole for the detection of metal and nonmetal ions such as $\mathrm{Hg}^{2+}$ and fluoride ions has been reported in the literature. ${ }^{(7,8)}$

Chitosan is poly ( $\beta-1-4)-2$-amino-2-deoxy-D-glucopyranose, and produced by a partial or full alkaline N-deacetylation of chitin until the degree of deacetylation of the chitin is more than $50 \%$. The chitin can dissolve in an aqueous acidic medium to produce chitosan. It is nontoxic, can be found in the exoskeleton of shellfish, and is a naturally abundant biopolymer. ${ }^{(9-11)}$

Chitosan is a chelating agent and can adsorb metal ions and proteins. The affinity for transition of the metal ion in chitosan is due to the abundant amino $\left(-\mathrm{NH}_{2}\right)$ and/or hydroxy $(-\mathrm{OH})$ groups on the chitosan chains. ${ }^{(9,12)}$ Hence, the amino group of chitosan is the principal group involved in binding metal ions. It is widely accepted that the metal ion via four amino groups in a square-planar geometry is immobilized on chitosan. ${ }^{(13,14)}$ The degree of deacetylation ${ }^{(15)}$ in chitosan is the main reason for the adsorption capacity of metal ions. The protonation of amine groups in acidic solutions is responsible for the electrostatic attraction.

On the other hand, the metal ions are absorbed by the free electron doublet of nitrogen on amine groups of metal anions. ${ }^{(9)}$ The copper ion, ${ }^{(16)}$ nickel ion, lead ion, ${ }^{(17)}$ mercury ion, ${ }^{(18)}$ and aluminium ion ${ }^{(19)}$ are examples of ions detected in an aqueous solution with chitosan. Burke et al. in 2002 removed the Fe(III) ion from solution using chitosan. ${ }^{(20)}$ Ngah et al. in 2005 used chitosan for the adsorption of $\mathrm{Fe}(\mathrm{II})$ and $\mathrm{Fe}(\mathrm{III})$ ions in an aqueous solution. They reported that under an equilibrium condition, the Langmuir model can describe the binding very well.(21) Wang et al. in 2008 investigated the adsorption of $\mathrm{Fe}(\mathrm{III})$ using carboxymethylated chitosan hydrogels. ${ }^{(22)}$

Essentially, the surface plasmon resonance (SPR) signals depend on the optical properties of the bilayer of metal and dielectric and relate to the charge density oscillation at the interface between them. ${ }^{(23)}$ One advantage of SPR is that the light beam does not pass through the mixture of interest, ${ }^{(24)}$ therefore, the measurement is free from any effect of the absorption of the light in the latter. Hence, SPR is a powerful method of retrieving information on concentration related to the optical properties of a biomaterial. ${ }^{(25)}$ If the parameters of the gold layer $(n, k)$ are known, and the resonance angle depends on the optical parameters of the mixture, the concentration of methanol in the mixture during transesterification can be determined by analyzing the SPR signal.

In this study, the effects of excess methanol and excess oil on the optical properties 
of virgin coconut oil biodiesel were first obtained using SPR. Then, the iron corrosion of virgin coconut oil biodiesel (VCOB) was monitored with an SPR sensor using the polypyrrole-chitosan (PPy-CHI) sensing layer.

\section{Materials and Methods}

\subsection{VCOB preparation}

In this experiment, we prepared a mixture of virgin coconut oil with methanol using the alkali-catalyzed transesterification method. The volume ratio of methanol to oil was from 0.9 to $0.12 \mathrm{v} / \mathrm{v}$ and the percentage of $\mathrm{NaOH}$ was $1.1 \% \mathrm{w} / \mathrm{v}$ of oil; the average reaction temperature was $60^{\circ} \mathrm{C}$. The optimum volume ratio of methanol to coconut oil was $0.4 \mathrm{v} / \mathrm{v}$ at the reaction temperature of approximately $60^{\circ} \mathrm{C}$ (sample A). ${ }^{(1)}$ The volume ratio of methanol to virgin coconut oil in the final product for samples $\mathrm{C}, \mathrm{B}$, and $\mathrm{D}$ were 0.67 , 0.38 , and $0.12 \mathrm{v} / \mathrm{v}$, respectively.

\subsection{Sensing layer}

The preparation of the PPy-CHI sensing layer is explained in ref. 26. Briefly, the sensing layer was deposited on a gold layer by electrochemical deposition. The potentiostat (Model: PS 605, USA) was used for the electrochemical deposition of PPy-CHI. The anodic potential of the working electrode was $1.1 \mathrm{~V}$ against a saturated calomel electrode. The polymers were potentiostatically prepared in a solution containing $0.3 \mathrm{M}$ pyrrole (predistilled), $0.1 \mathrm{M} p$-toluene sulfonate (P-TS) dopant, and $0.7 \%$ $\mathrm{w} / \mathrm{v} \mathrm{CHI}$ in acetic acid at room temperature.

\section{$2.3 \mathrm{Fe}^{3+}$ solution}

The $\mathrm{Fe}^{3+}$ aqueous solutions were prepared with $\mathrm{Fe}_{2}\left(\mathrm{SO}_{4}\right)_{3}$. For this purpose, $1 \mathrm{~g}$ of $\mathrm{Fe}_{2}\left(\mathrm{SO}_{4}\right)_{3}$ was dissolved in $1 \mathrm{~L}$ of DI water, resulting in a 1000 ppm $\mathrm{Fe}_{2}\left(\mathrm{SO}_{4}\right)_{3}$ solution. Then, other concentrations $(0.1,1,5,10,50$, and $75 \mathrm{ppm})$ were prepared by the systematic dilution of the $1,000 \mathrm{ppm} \mathrm{Fe}_{2}\left(\mathrm{SO}_{4}\right)_{3}$ solution.

\subsection{SPR analysis}

The condition of surface plasmon resonance depends on the refractive index of the gold layer and probed medium as follows:

$$
n_{\mathrm{p}} \sin \theta_{\mathrm{R}}=\sqrt{\left(n_{1}^{2} n_{2}^{2}\right) /\left(n_{1}^{2}+n_{2}^{2}\right)}
$$

where $\theta_{\mathrm{R}}, n_{\mathrm{p}}, n_{1}$, and $n_{2}$ are the resonance angle and refractive indices of the prism, gold layer, and probed medium, respectively. ${ }^{(27)}$ The refractive index of the probed medium is

$$
n_{2}=\sqrt{\left(n_{1}^{2} n_{\mathrm{p}}^{2} \sin ^{2} \theta_{\mathrm{R}}\right) /\left(n_{1}^{2}-n_{\mathrm{p}}^{2} \sin ^{2} \theta_{\mathrm{R}}\right)} .
$$


If $A$ is the angle of the prism and $\theta_{1}$ is the angle of incidence of the light beam directed to the prism, the angle of incidence on the metal layer is obtained as

$$
\theta_{2}=A-\arcsin \left[\left(n_{\text {air }} / n_{\mathrm{p}}\right) \sin \theta_{1}\right],
$$

where $n_{\text {air }}$ is the refractive index of air.

If the angle of incidence at the interface between the prism and gold layer is obtained using eq. (3), the refractive index of the mixture can be determined by minimizing the $\operatorname{sum}^{(28)}$

$$
\Gamma=\sum_{\theta}\left[R_{\mathrm{Exp}}\left(\theta_{2}\right)-R_{\text {Theory }}\left(\theta_{2}\right)\right]
$$

where $R_{\text {Exp }}$ and $R_{\text {Theory }}$ are the experimental and theoretical reflectivities respectively, and are functions of angle and wavelength.

\subsection{SPR experiment for characterizing virgin coconut oil biodiesel}

The SPR setup in Fig. 1 consists of a precision rotation stage, a high-index prism (SF52 FocTek), a silicon photodetector, a polarizer, a chopper (SR540 Stanford Research system), a lock-in amplifier, and a laser $(632.8,594.1,543.5$, and $405 \mathrm{~nm}){ }^{(29)}$ The rotation stage and photodetector were controlled using a program written with Matlab. In this setup, the rotation stage was connected to a stepper motor where the minimum angle of rotation was $0.016^{\circ}$. The prism was first adjusted to its start point before being rotated up to $25^{\circ}$ via incremental $0.016^{\circ}$ steps. At each step, the rotation stage was momentarily stopped, so the light intensity could be determined by the silicon photodetector connected to the lock-in amplifier. ${ }^{(24)}$

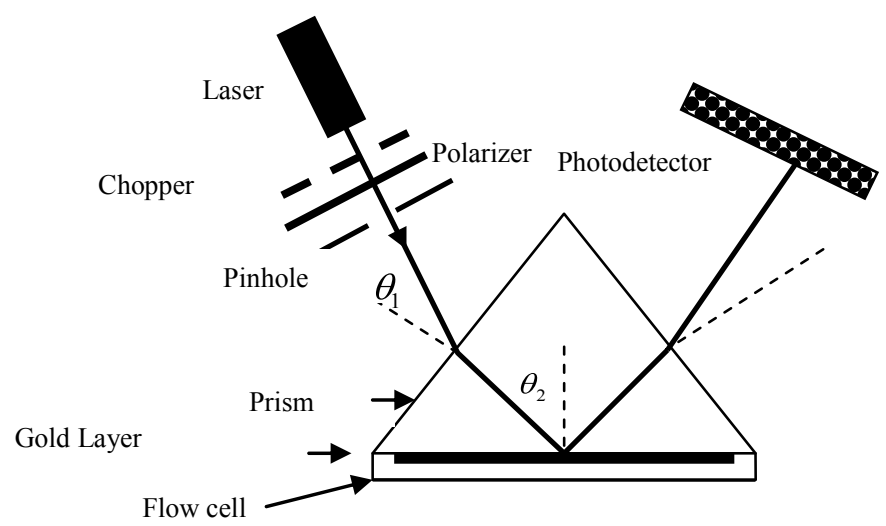

Fig. 1. Experimental setup includes a light source, a polarizer, a chopper, a pinhole, a prism, a flow cell, and a detector. 
All the measurements were carried out with the mixture being in direct contact with the gold layer of $52.5 \mathrm{~nm}$ thickness. The SPR signals were registered for various wavelengths as well, such as 632.8 (red), 594.1(yellow), 543.5 (green), and $405 \mathrm{~nm}$ (violet).

In addition, the minimum deviation method using a hollow prism was used to measure the refractive indices in $644.8,589.3,578.2,546$, and $435.8 \mathrm{~nm} .{ }^{(30)}$ The light beam from $\mathrm{Cd}, \mathrm{Na}$, and $\mathrm{Hg}$ lamps was utilized to obtain the dispersion curve.

\subsection{SPR sensor experiment}

In this experiment, the SPR sensor setup is shown in Fig. 1. The gold layer and sensing layer (PPy-CHI) were deposited on a prism. The thicknesses of the gold layer and sensing layer (PPy-CHI) were 49 and $20.4 \mathrm{~nm}$, respectively. A flow cell was then installed on the prism.

First, the baseline was determined with the distilled water that passed through the flow cell and had direct contact with the sensing layer. Then, a stable baseline was achieved; the setup and $\mathrm{PPy}-\mathrm{CHI}$ sensing film were ready to measure the concentration of iron ions in the aqueous solution.

Each different concentration of the $\mathrm{Fe}^{3+}$ aqueous solution was allowed in physical contact with the PPy-CHI layer, and the SPR signal was then recorded. The sensorgrams were drawn for different concentrations of iron ions in the aqueous solution.

An iron strip was immersed in $50 \mathrm{ml}$ of each of the four VCOB samples at $50^{\circ} \mathrm{C}$ for 5 h. Then, each sample was allowed in physical contact with the sensing layer (PPy-CHI) using a flow cell and the SPR signals were then recorded ten times.

Ions are presumed to have accumulated on the sensing layer during the binding process. Hence, the refractive index near the PPy-CHI layer and the thickness of the bound ions layer ${ }^{(31,32)}$ changed. Consequently, the resonance angle shifted to a larger value. The matrix method was utilized ${ }^{(32)}$ to determine the shift of the refractive index and the thickness.

\subsection{Atomic absorption spectroscopy (AAS)}

Atomic absorption spectroscopy (AAS; Thermo Scientific model S series) was utilized to determine the concentration of iron ions in virgin coconut oil biodiesel samples. For this measurement, the spectroscope was calibrated with $\mathrm{Fe}_{2}\left(\mathrm{NO}_{3}\right)_{3}$ in $\mathrm{HNO}_{3}$ solution $(1,3$, and $5 \mathrm{ppm})$.

\section{Results and Discussion}

\subsection{Characterizing virgin coconut oil biodiesel}

Figure 2 shows the SPR signals for the mixture of virgin coconut oil and methanol. The experiment was performed with a He-Ne laser $(632.8 \mathrm{~nm})$ at room temperature. Solid lines are the fitted curves of the Fresnel equation ${ }^{(24,27)}$ to the experimental data by minimizing eq. (4). When the volume percentage of virgin coconut oil increased in the range of $10-90 \%$, the resonance angle increased from 53.985 to $60.24^{\circ}$, while the refractive index increased from 1.3426 to 1.4246 , as summarized in Table 1.

Figure 3 shows the variation in the refractive index with the concentration of the 

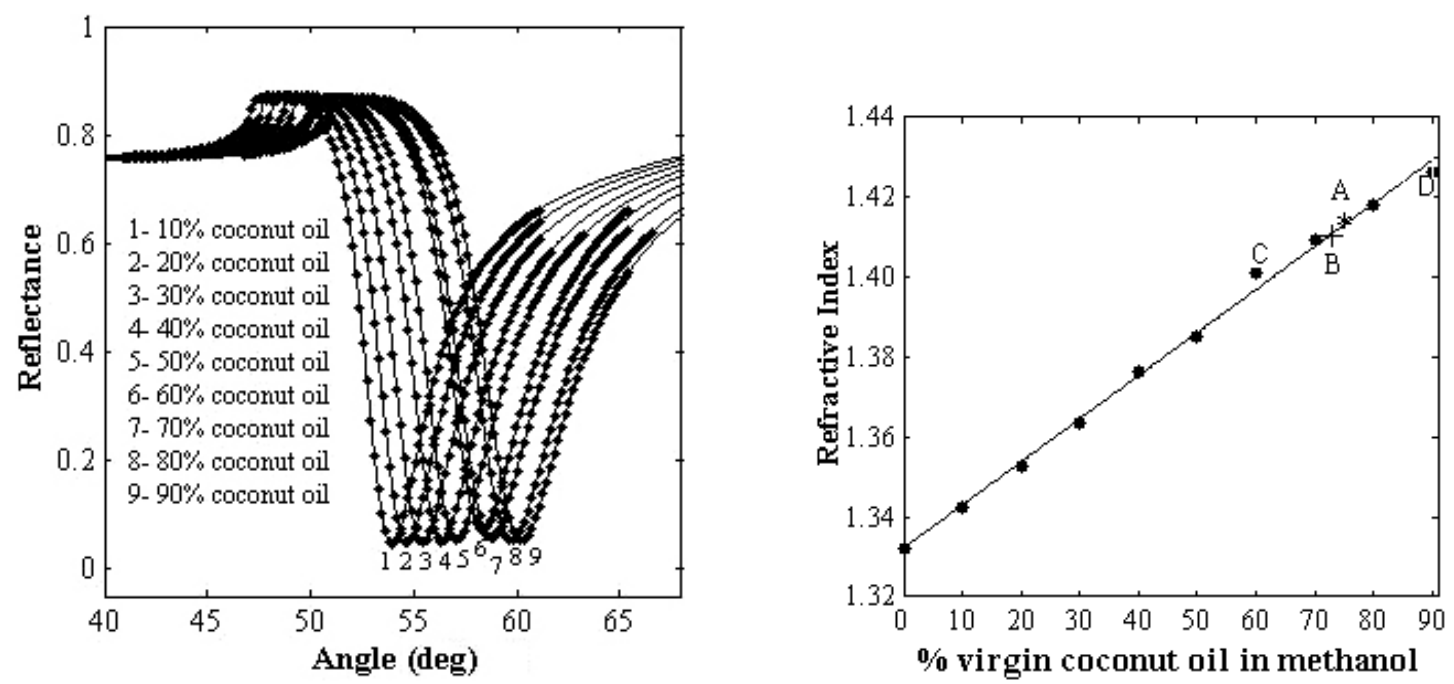

Fig. 2 (left). SPR signals for the mixture of coconut oil and methanol; the percentage of coconut oil was changed from 10 to $90 \%$.

Fig. 3 (right). Refractive index of the respective volume percentage of virgin coconut oil in the biodiesel mixture (Dot $(\bullet)$ indicates experimental data and solid line is the fitted curve).

Table 1

Resonance angles and refractive indices of the mixture of virgin coconut oil and methanol.

\begin{tabular}{cccc}
\hline $\begin{array}{c}\text { Percentage of } \\
\text { virgin coconut oil } \\
\%\end{array}$ & $\begin{array}{c}\text { Volume ratio } \\
\text { (methanol to oil) } \\
\mathrm{v} / \mathrm{v}\end{array}$ & $\begin{array}{c}\text { Resonance } \\
\text { Angle } \\
\left(\theta_{\mathrm{p}} \pm 0.016\right)^{\circ}\end{array}$ & $\begin{array}{c}\text { Refractive } \\
\text { index } \\
\Delta n= \pm 0.0001\end{array}$ \\
\hline 10 & 9 & 53.985 & 1.3426 \\
\hline 20 & 4 & 54.705 & 1.3528 \\
\hline 30 & 2.4 & 55.470 & 1.3635 \\
\hline 40 & 1.5 & 56.415 & 1.3763 \\
\hline 50 & 1 & 57.090 & 1.3852 \\
\hline 60 & 0.67 & 58.335 & 1.4013 \\
\hline 70 & 0.43 & 58.950 & 1.4090 \\
\hline 80 & 0.25 & 59.715 & 1.4183 \\
\hline 90 & 0.12 & 60.240 & 1.4246 \\
\hline
\end{tabular}

virgin coconut oil derived from the data in Table 1. As shown in Fig. 3, the variation in the refractive index with the concentration of oil was linear. Since the refractive index of biodiesel ester is higher than that of methanol and less than the refractive index of virgin coconut oil, the refractive index and concentration of the mixture (volume ratio of methanol to oil) at point A were about 1.4122 and $0.362 \mathrm{v} / \mathrm{v}$, respectively. The standard volume ratio (Point $\mathrm{B}$ ) was $0.4 \mathrm{v} / \mathrm{v}$ and the refractive index was 1.405 . The difference between the concentrations was about 0.038 but the angle shift was $0.556^{\circ}$, which is 
much larger than the precision of the rotation angle $\left(0.016^{\circ}\right)$.

Since the ratio of methanol to oil for sample A was considered optimum, Figs. 4 and 5 were plotted to show the respective SPR signals for different wavelengths and the dispersion curve of the sample A. Experimental constants for the Augustin Louis Cauchy formula, ${ }^{(30)}$

$$
n^{2}=1+\frac{b_{1} \lambda^{2}}{\lambda^{2}-c_{1}}+\frac{b_{2} \lambda^{2}}{\lambda^{2}-c_{2}},
$$

were obtained. The refractive index decreased from 1.4239 to 1.4118 with the increase in the wavelength, as derived from the data in Table 2.
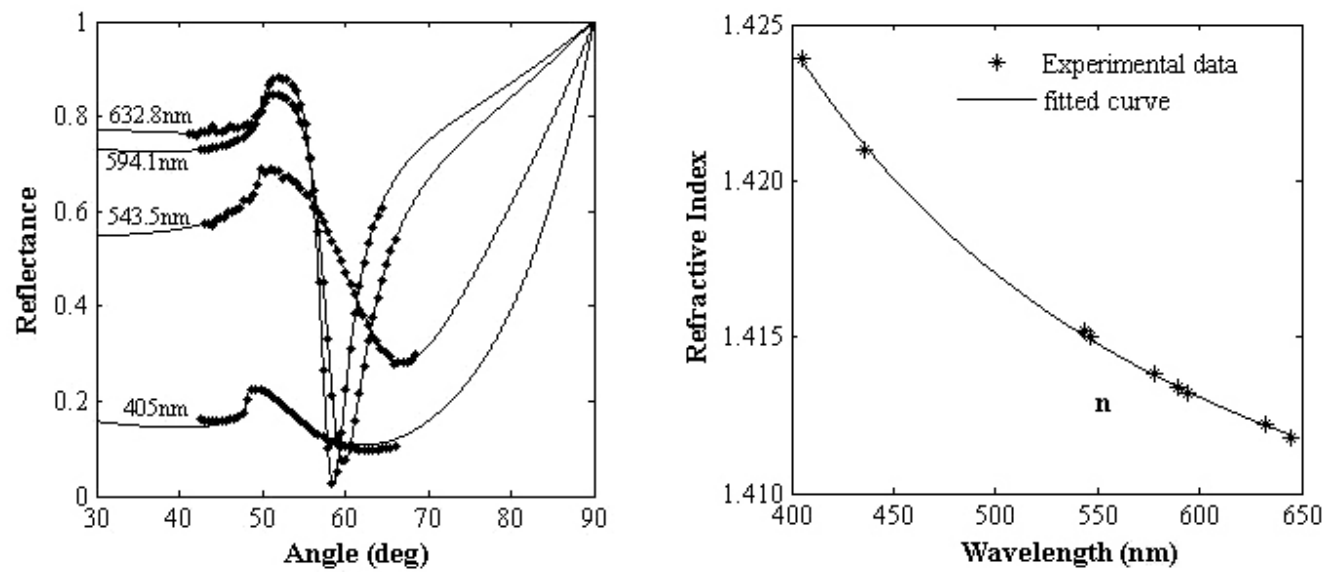

Fig. 4 (left). SPR signals of VCOB with various wavelengths (Dot ( $\mathbf{m})$ indicates experimental data and solid lines are the fitted curves).

Fig. 5 (right). Dispersion curve for VCOB for various wavelengths from red to blue light (The star $(*)$ indicates experimental data and the solid line is the fitting of eq. (5)).

Table 2

Refractive index of biodiesel (Sample A) for various wavelengths.

\begin{tabular}{cc}
\hline Wavelength $(\mathrm{nm})$ & Refractive index \\
\hline 644.8 & 1.4118 \\
\hline 632.8 & 1.4122 \\
\hline 594.1 & 1.4132 \\
\hline 589.3 & 1.4134 \\
\hline 578.2 & 1.4138 \\
\hline 546.0 & 1.4150 \\
\hline 543.5 & 1.4152 \\
\hline 435.8 & 1.4210 \\
\hline 405.0 & 1.4239 \\
\hline Constants & $b_{1}=70.32, b_{2}=-69.35$, \\
& $c_{1}=78.6, c_{2}=-55.91$ \\
\hline
\end{tabular}




\subsection{SPR sensor for detection of iron corrosion}

Plot 1 in Fig. 6 shows the SPR signal for distilled water (baseline). The resonance angle is $58.13^{\circ}$. Plots $2,3,4$, and 5 (Fig. 6) are the SPR signals (baseline) for the biodiesel samples $\mathrm{B}, \mathrm{A}, \mathrm{D}$, and $\mathrm{C}$, respectively. These signals were obtained before dipping the iron strip into the biodiesel samples, and the recorded resonance angles are sorted in Table 3. Figure 7 shows the sensorgrams for the different concentrations of
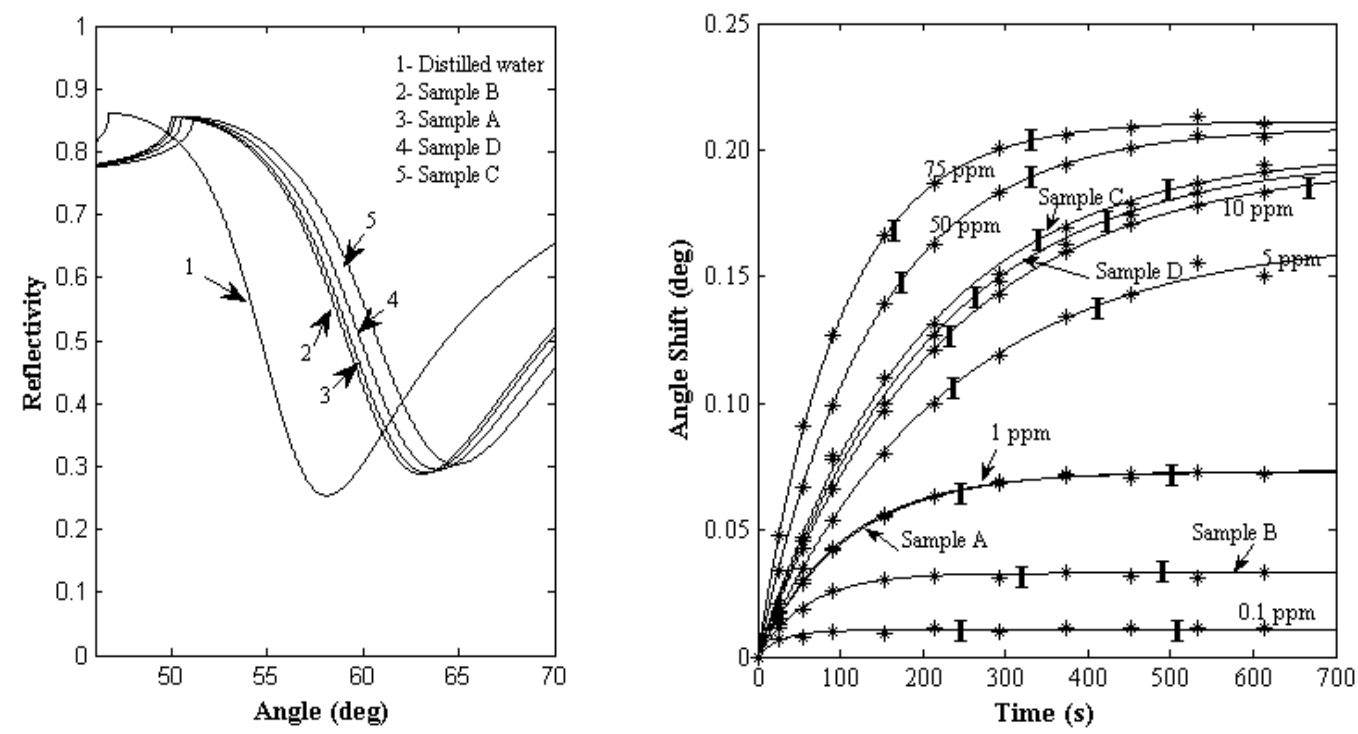

Fig. 6 (left). SPR signals at baseline.

Fig. 7 (right). Sensorgram for each concentration of $\mathrm{Fe}^{2+}$ in aqueous solution and biodiesel (samples A, B, C, and D).

Table 3

Pertinent SPR sensor parameters and samples.

\begin{tabular}{|c|c|c|c|c|c|}
\hline Measurement & & Sample A & Sample B & Sample C & Sample D \\
\hline $\begin{array}{l}\text { Copper strip corrosion } \\
\left(3 \mathrm{~h} \text { at } 50^{\circ} \mathrm{C}\right) \\
(\text { ASTM D6751) }\end{array}$ & & $1 \mathrm{a}$ & $1 \mathrm{a}$ & $4 a$ & $4 a$ \\
\hline $\begin{array}{l}\text { Water content } \\
(\text { ASTM D6751) }\end{array}$ & & $270 \mathrm{ppm}$ & $200 \mathrm{ppm}$ & $1,500 \mathrm{ppm}$ & $300 \mathrm{ppm}$ \\
\hline AAS: Absorption & & 0.11 & 0.035 & 1.286 & 1.141 \\
\hline Equivalent $\mathrm{Fe}^{2+}$ & $a$ & $0.955 \mathrm{ppm}$ & $0.308 \mathrm{ppm}$ & $17.17 \mathrm{ppm}$ & 15.186 \\
\hline SPR: Baseline & & 63.93 & 63.382 & 63.103 & 64.887 \\
\hline Final value & & 0.072 & 0.031 & 0.194 & 0.191 \\
\hline$k_{\mathrm{a}}$ & & 0.009157 & 0.01622 & 0.005073 & 0.004794 \\
\hline Equivalent $\mathrm{Fe}^{2+}$ & $b$ & $0.998 \mathrm{ppm}$ & $0.352 \mathrm{ppm}$ & $17.444 \mathrm{ppm}$ & $15.088 \mathrm{ppm}$ \\
\hline$|a-b|$ & & 0.043 & 0.044 & 0.274 & 0.098 \\
\hline
\end{tabular}


the $\mathrm{Fe}^{3+}$ solution used to calibrate the SPR sensor for the detection of the iron ions. As shown in Fig. 7, the resonance angle shift $(\Delta \theta)$ increased with time, and after about $400 \mathrm{~s}$, the resonance angle shift was approximately constant at a corresponding final value. Figure 8 shows the SPR signals at the final resonance angle value. The experimental data in Fig. 7 (* and $\bullet$ ) were fitted to the Langmuir equation (eq. (6)) as ${ }^{(32)}$
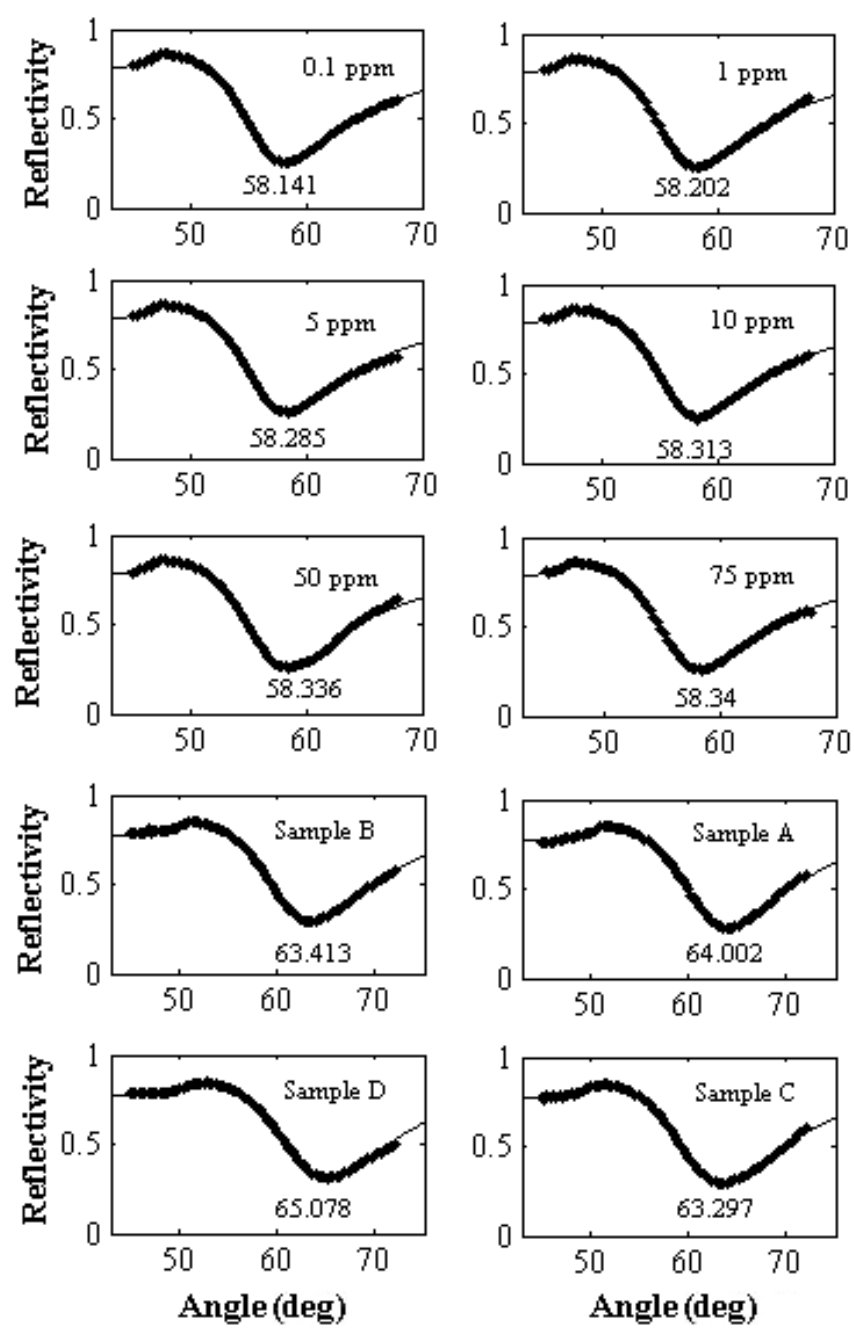

Fig. 8. SPR signals at final value of resonance angle shift for different concentrations of $\mathrm{Fe}^{2+}$ solution and biodiesel samples. 


$$
\Delta \theta(t)=\Delta \theta_{\text {ter }}\left[1-\exp \left(k_{\alpha} t\right)\right]
$$

where $\Delta \theta_{\text {ter }}$ is the final value of the resonance angle shift and $k_{\alpha}$ is the rate constant of the sensing layer.

Figure 9 shows the plot of the angle shift at the final value versus the concentration of iron ions, and the experimental data were fitted to the Langmuir adsorption model as follows:

$$
\Delta \theta=\frac{\Delta \theta_{\mathrm{Ex}} c}{\frac{1}{\mathrm{~K}}+c},
$$

where $c$ is the ion concentration, $\mathrm{K}$ is the affinity constant, and $\Delta \theta_{\mathrm{Ex}}$ is the maximum value for the resonance angle shift. ${ }^{(33)}$ The concentrations of the biodiesel samples were obtained from Fig. 9. Hence, the pertinent parameters are sorted in Table 3.

Figure 10 shows the AAS results for different concentrations of $\mathrm{Fe}^{3+}$ in biodiesel. Hence, the concentrations of $\mathrm{Fe}^{3+}$ in samples $\mathrm{B}, \mathrm{A}, \mathrm{D}$, and $\mathrm{C}$ are $0.308,0.955,15.861$, and $17.444 \mathrm{ppm}$, respectively, which are comparable to the SPR results in Table 3. The correlation between SPR and AAS results, as shown in Fig. 11, is 95\%.

The data show that the highest concentration of iron ions in sample $\mathrm{C}$ is due to the water content being highest in sample $\mathrm{C}$ than in the other samples (Table 3), even though, sample $\mathrm{C}$ has the lowest free fatty acid content (Fig. 3). This shows that water causes more severe corrosion than fatty acids.

\section{Conclusions}

Surface plasmon resonance was found to be a suitable method of determining the concentration of methanol in $\mathrm{VCOB}$, and can be used to control the concentration of

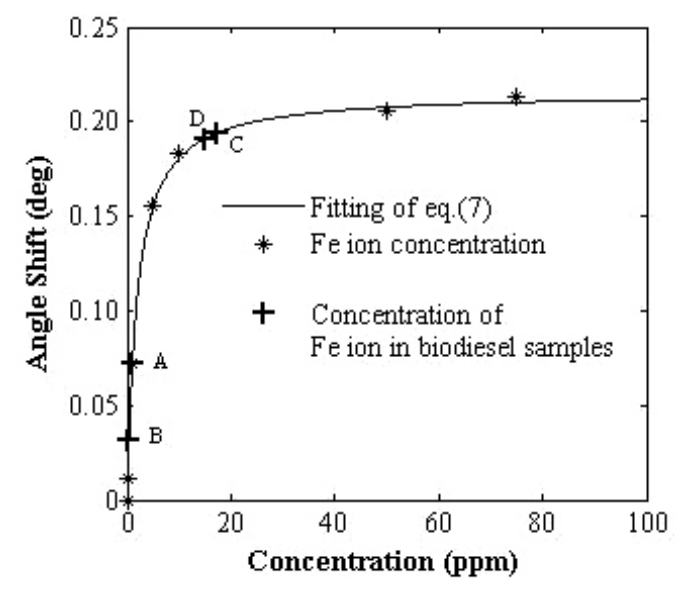

Fig. 9. Variation of angle shift versus concentration of iron ions. 

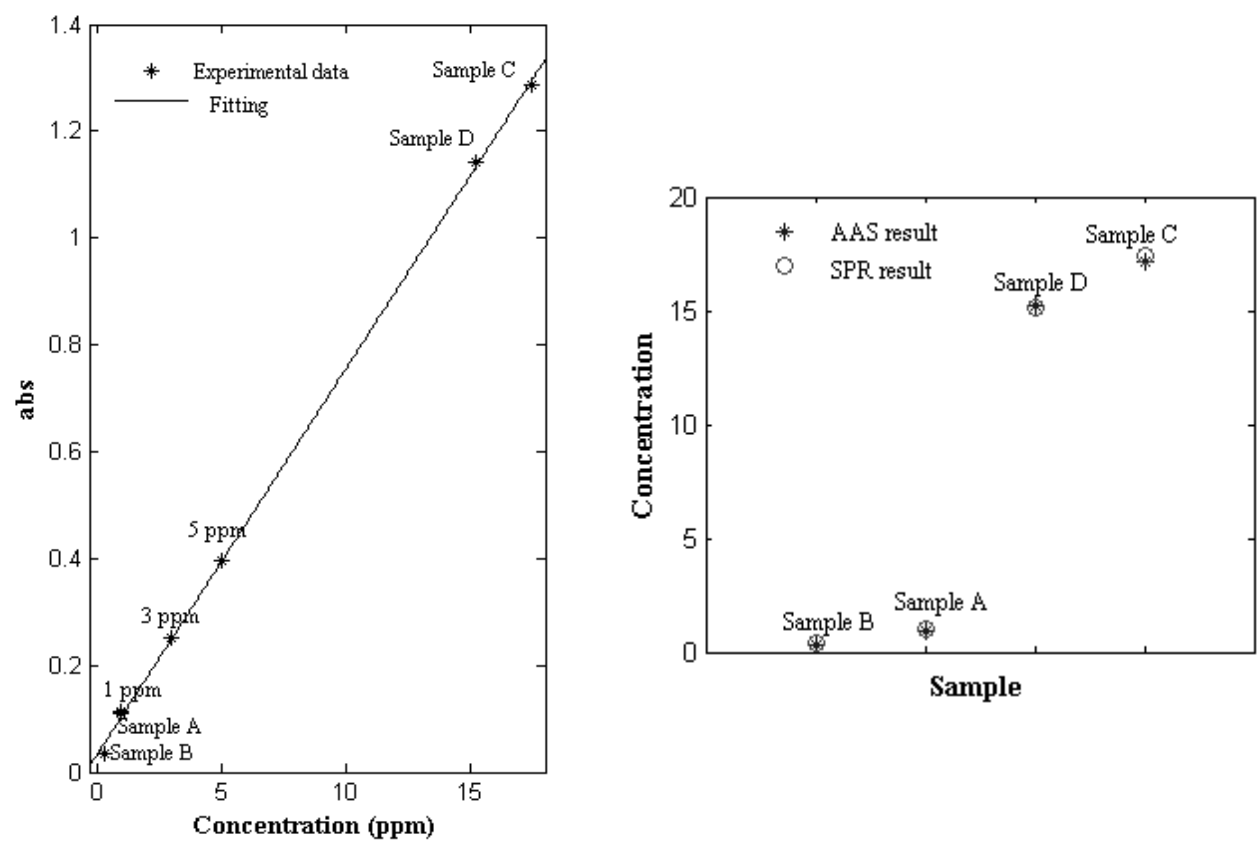

Fig. 10 (left). AAS result. The spectroscope was calibrated with $\mathrm{Fe}_{2}\left(\mathrm{NO}_{3}\right)_{3}$ in $\mathrm{HNO}_{3}$ solution $(1,3$, and $5 \mathrm{ppm})$.

Fig. 11 (right). Correlation between SPR measurement and AAS measurement.

excess methanol in the final product. This method is noninvasive and nondestructive for characterizing the biodiesel. The iron corrosion of VCOB not only depends on the free fatty acid but also on the water content. The SPR sensor with the PPy-CHI sensing layer was capable of detecting the concentration of iron ions as low as about $0.1 \mathrm{ppm}$. It is a convenient method of evaluating the iron corrosion of virgin coconut oil biodiesel.

\section{Acknowledgment}

The first author (A. R. Sadrolhosseini) thanks Universiti Putra Malaysia for the Graduate Research Fellowship (GRF).

\section{References}

1. P. Nakpong and S. Wootthikanokkhan: Renewable Energy 35 (2010) 1682.

2. R. Sridharan and I. M. Mathai: J. Sci. Ind. Res. 33 (1974) 178.

3. J. V. Gerpen, B. Shanks, R. Pruszko, D. Clements and G. Knothe: Biodiesel Analytical Methods (National Renewable Energy Laboratory, Colorado, USA, 2004) p. 32. 
4. J. N. Barisci, G. G. Wallace, M. K. Andrews, A. C. Partidge and P. D. Harris: Sens. Actuators, B 84 (2002) 252.

5. K. Khalid, I. V. Grozescu, L. K. Tiong, L. T. Sim and R. Mohd: Meas. Sci. Technol. 14 (2003) 1905 .

6. S. Sadki, P. Schottland, N. Brodie and G. Sabouraud: Chem. Soc. Rev. 29 (2000) 283.

7. J. C. C. Yu, E. P. C Lai and S. Sadeghi: Sens. Actuators, B 101 (2004) 236.

8. M. Karthikeyan, K. K. Satheeshkumar and K. P. Elango: J. Hazard. Mater. 167 (2009) 300.

9. E. Guibal: Separation and Purification Technology 38 (2004) 43.

10. M. N. V. Ravi Kumar: React. Funct. Polym. 46 (2000) 1.

11. S. M. Nomanbhay and K. Palanisamy: Electron. J. Biotechnol. 8 (2005) 43.

12. O. A. C. Monteiro and C. J. Airoldi: Colloid Interface Sci. 212 (1999) 212.

13. K. Kofuji, Y. Murata and S. Kawashima: Int J. Pharm. 303 (2005) 95.

14. F. Li, P. Du, W. Chen and S. Zhang: Anal Chim. Acta. 585 (2007) 211.

15. V. E. Tikhonov, L. A. Radigina and Y. A. Yamskov: Carbohydr. Res. 290 (1996) 33.

16. P. Bai, F. Cao, X. Lan, F. Zhao, Y. Ma and C. Zhao: J. Biochem. Biophys. Methods 70 (2008) 903.

17. A. T. Paulino, M. R. Guilherme, A. V. Reis, E. B. Tambourgi, J. Nozaki and E. C. Muniz: J. Hazard. Mater. 147 (2007) 139.

18. P. Miretzky and A. F.Cirelli: J. Hazard. Mater. 167 (2009) 10.

19. C. Septhum, S. Rattanaphani, J. B. Bremner and V. Rattanaphani: J. Hazard. Mater. 148 (2007) 185.

20. A. Burke, E. Yilmaz, N. Hasirci and O. Yilmaz: J. Appl. Polym. Sci. 84 (2002) 1185.

21. W. S. W. Ngah, S. A. Ghani and A. Kamari: Bioresource Technology 96 (2005) 443.

22. M. Wang, L. Xu, M. Zhai, J. Peng, J. Li and G. Wei: Carbohydr. Polym. 74 (2008) 498.

23. N. Peyghambarian, S. W. Koch and A. Mysyrowicz: Introduction to Semiconductor Optics, (Prentice Hall, Englewood Cliffs, New Jersey, 1993).

24. A. R. Sadrolhosseini, M. M. Moksin, W. M. M.Yunus and Z. A. Talib: J. Eng. Appl. Sci. (ARPN) $5(2010) 54$.

25. P. Englebienne, A.V. Hoonacker and M. Verhas: Spectroscopy 17 (2003) 255.

26. M. M. Abdi, A. Kassim, H. N. M. E. Mahmud, W. M. M. Yunus, Z. A. Talib and A. R. Sadrolhossreini: J. Mater. Sci. 44 (2009) 3682.

27. J. Homola: Surface Plasmon Resonance Based Sensors, (Springer-Verlag, Berlin, Heidelberg, 2006) p.27.

28. A. J. Jääskeläinen, K.-E. Peiponen and J. A. Räty: J. Dairy Sci. 84 (2001) 38.

29. W. Y. W. Yusmawati, H. P. Chuah and W. M. M. Yunus: Am. J. Appl. Sci. 4 (2007) 1.

30. M. M. W. Yunus and A. R. Azizan: Appl. Opt. 27 (1988) 3341.

31. S. Chah, J. Yi and R. N. Zare: Sens. Actuators, B 99 (2004) 216.

32. R. B. M. Schasfoort and A. J. Tudos: Handbook of Surface Plasmon Resonance (Royal Society of Chemistry, Cambridge, UK, 2008) p. 50.

33. E. S. Forzani, H. Q. Zhang, W. Chen and N. J. Tao: Environ. Sci. Technol. 39 (2005) 1257. 